\title{
Wild type root cultures of Scutellaria barbata
}

\author{
agata Wilczańska-Barska, Mirostawa KraUze-Baranowska*, \\ Magdalena MaJdAN, DANiEl GŁóD \\ Department of Pharmacognosy with Medicinal Plant Garden, Medical University of Gdańsk, Poland \\ *Corresponding author: krauze@gumed.edu.pl
}

\begin{abstract}
Scutellaria barbata wild type root cultures were grown on liquid media: Gamborg (B5) and Schenk-Hildebrandt (SH) supplemented with (1 mg/l) indole-3-butyric acid (IBA). For each culture, growth rate and secondary metabolites production were determined. It was observed that in the metabolic profiles, the dominating compounds were flavone glycosides - wogonoside, baicalin and phenylethanoid glycoside acteoside. Aglycones namely wogonin, baicalein and chrysin - were present at low concentrations. On B5 medium, the average productivity of plant material counted as the sum of flavones was higher (ca. $1300 \mathrm{mg} / \mathrm{l}$ ) than on SH medium (ca. $999 \mathrm{mg} / \mathrm{l}$ ). In order to remove the compounds that cause browning of the medium and inhibit culture growth, especially on B5 IBA 1.0 medium, a number of experiments with the addition of cork pieces, citric acid and Amberlite XAD-4 and XAD-7 resins into the culture media were performed. The best growth of the root culture was achieved on B5 medium supplemented with - $1.0 \mathrm{mg} / \mathrm{l} \mathrm{IBA}$ along with the addition of $7 \mathrm{mg} / \mathrm{ml}$ of cork and with $10 \mathrm{mg} / \mathrm{ml}$ of Amberlite XAD-4 resin, although concentrations of the analyzed metabolites were lowers than in the control group.
\end{abstract}

Key words: Scutellaria barbata, flavones, wild type root cultures

\section{Abbreviations}

$\begin{array}{ll}\text { AU } & \text { - absorbance unit } \\ \text { FW }(g / 1) & \text { - fresh weight } \\ \text { DW }(g / l) & \text { - dry weight }\end{array}$

\section{Introduction}

Various plant parts (leaves, herbs, fruits, seeds) are a source of herbal remedies and chemical compounds (secondary metabolites) with different pharmacological activities. The alternative way of obtaining secondary metabolites are in vitro cultures of higher plants, and, among others, root cultures. Root cultures can be divided into two groups - the nontransformed (wild type) ones and the hairy (transformed, transgenic) root cultures (Cui, Chakrabarty, Lee and Paek, 2010; Wysokińska and Chmiel, 2006). Majority of the biotechnological studies have focused on hairy root cultures which are characterized by fast growth rate, high productivity and genetic stability (Wysokińska and Chmiel, 2006).

There are a number of experiments described in the literature that compare wild type root cultures with
Gf (\%) - growth factor established by the formula: $\mathrm{Gf}=\mathrm{FW}_{\text {final }}-\mathrm{FW}_{\text {initial }} / \mathrm{FW}_{\text {initial }} \times 100$

hairy root cultures in terms of biotechnological parameters. In many cases, it has been observed that hairy root cultures demonstrate a higher productivity of secondary metabolites (e.g., Plantago lanceolata, Datura stramonium, Scutellaria baicalensis) (Fons et al., 1999; Baiza et al., 1998; Tiwari et al., 2008). An exception is Coluria geoides wild type root cultures which accumulate higher concentrations of eugenol, the main compound of essential oil, than hairy root clones (Olszowska et al., 1996).

An interesting illustration of productivity of such wild type root cultures is co-culture of normal roots of two species, Echinacea purpurea and Panax ginseng which, besides ginsenosides, produce caffeic acid derivatives (Wu et al., 2008). Another example is the Hypericum perforatum wild type root culture that grows in 
a bioreactor accumulating naphtodiantrones such as hypericin and pseudohypericin (Cui et al., 2010).

Scutellaria barbata D. Don (Lamiacae) is a plant that is widely distributed in China, India, Nepal, Korea and Vietnam (Świąder et al., 2003). In traditional Chinese medicine, it is known as Ban-Zhi-Lian or Ban-Ji-Ryun. This herbal medicine, as described in the Chinese Pharmacopeia, is, in fact, the dried aerial parts collected after the flowering stage. The herb is used as an anti-inflammatory, antipyretic and antiallergic agent, both externally, for treating skin inflammations, and internally, in allergic reactions or inflammations and cirrhosis (Świąder et al., 2003; Wang et al., 2008; Yin et al., 2004).

In many Asian countries, extracts from $S$. barbata are also employed in anticancer therapies. It has been confirmed from many in vitro and clinical studies that these extracts have the ability to inhibit cancerous cell growth. The effectiveness of $S$. barbata extracts has also been observed in the treatment of lung, digestive system, ovarian, and breast cancers, as well as in uterine leiomyoma (Yin et al., 2004; Lee et al., 2004; Powell et al., 2003; Rugo et al., 2007; Fong, 2008).

The main compounds that confer medicinal properties to $S$. barbata aerial parts are flavones that include inter alia: scutellarin, wogonin, baicalin, baicalein and luteolin (Świąder et al., 2003; Wang et al., 2008; Yin et al., 2004).

The mechanism of flavone anticancer action is based on the induction of apoptosis by the inhibition of cell cycle and influence on pro- and antiapoptotic proteins (Wilczańska-Barska, Chmura and Krauze-Baranowska, unpublished data). In the aerial parts of $S$. barbata, biologically active neo-clerodane alkaloids (scutebarbatins) (Dai et al., 2006; Dai et al., 2008) and pheophorbide, a chlorophyll derivative (Xu et al., 2010), are present. The dominating compound is scutellarin, whose concentration is used as a criterion for estimating the quality of S. barbata (Hu et al., 2008).

The chemical composition of $S$. barbata roots, as opposed to the roots of another valuable species from the genus Scutellaria - S. baicalensis, remains unknown. Thus far, no data regarding in vitro tissue cultures for $S$. barbata have been available.

The aim of the presented work was to establish $\mathrm{Scu}$ tellaria barbata wild type root cultures and to assess their ability to biosynthesize valuable secondary metabolites, mainly flavones.

\section{Materials and methods}

\section{In vitro cultures}

Seeds of five species from the genus Scutellaria were selected. S. lateriflora was obtained from the Botanical Garden at the University in Giessen (Germany), $S$. barbata from the Botanical Garden in Beijing (China), $S$. orientalis, $S$. albida and $S$. altissima were obtained from the Botanical Garden at the University in Gent (Belgium).

The seeds were stratified at $4{ }^{\circ} \mathrm{C}$ for 14 days. They were initially surface sterilized with a solution of a detergent (1 $\mathrm{min})$, then rinsed with water (30 $\mathrm{min})$ and placed in a $70 \%$ ethanol solution. Sterilization was carried out under aseptic conditions using $0.05 \%$ solution of mercuric chloride $\left(\mathrm{HgCl}_{2}, 15 \mathrm{~min}\right)$. After $15 \mathrm{~min}$, the seeds were rinsed thrice with re-distilled water (15 $\mathrm{min}$ ). The sterile seeds were placed on Petri dishes, using filter paper soaked in water. Sprouting process was conducted in the dark, in an incubator at $23^{\circ} \mathrm{C}$. Young seedlings ca $2 \mathrm{~cm}$ long, were transferred into the stationary nutrient (hormone-free MS medium). Four-week-old seedlings with well-developed root system were assigned for the induction of wild type root cultures. Young roots ca $2 \mathrm{~cm}$ long, with apical meristem were transferred to a liquid nutrient medium MS, Schenk-Hildebrandt (SH) and Gamborg (B5) supplemented with indole-3-butyric acid (IBA) at various concentrations (1.0, 5.0, 10.0 and $15.0 \mathrm{mg} / \mathrm{l})$. The roots were grown in a $16-\mathrm{h}$ photoperiod, in a 60-days cycle. The obtained cultures were able to biosynthesize chlorophyll.

In order to determine the growth and production profiles, optimal ratio of the inoculum to the volume of medium was established from the following proportions (g tissue/ml medium): $0.3 \mathrm{~g} / 30 \mathrm{ml}, 0.3 \mathrm{~g} / 50 \mathrm{ml}$, $0.5 \mathrm{~g} / 50 \mathrm{ml}, 1.0 \mathrm{~g} / 50 \mathrm{ml}, 5.0 \mathrm{~g} / 100 \mathrm{ml}$ and $10.0 \mathrm{~g} / 100 \mathrm{ml}$. Best growth rate was observed with the ratio of $1.0 \mathrm{~g}$ inoculum for $50 \mathrm{ml}$ medium.

\section{Chromatographic analysis}

\section{TLC analysis}

TLC analysis was performed on $10 \times 20 \mathrm{~cm}$ glass plates coated with modified silica gel (RP-18F 254S, Merck, Germany). Standards and samples were applied to the plates by using Desaga (Nümbrecht, Germany) AS-30 sample applicator. Separation was performed with the use of a mobile phase that consisted of methanol:water:formic acid (70:30:6, v/v/v). Analysis was carried out 
at the room temperature. Densitograms were obtained using a Desaga CD-60 densitometer at $\lambda=254 \mathrm{~nm}$.

\section{HPLC analysis}

\section{HPLC system}

The HPLC system consisted of a pump (model L7100), UV-VIS detector (model L-7420, Merck Hitachi), valve Rheodyne (RM-7125) with $1 \mu$ l volume and thermostat Jetstream II Plus (WO Industrial Electronics, Austria), working under computer control (interface Knauer V7566, 0696 version, with Eurochrom 2000, Knauer software for data handling). HSC 18 column $(7.5 \mathrm{~cm} \times 2.1 \mathrm{~mm}$ $\times 3 \mu \mathrm{m}$ ) from Supelco (USA) was used.

\section{Mobile phases}

Mobile phases were prepared using HPLC grade organic solvents: acetonitrile (POCH, Polska), trifluoracetic acid (Sigma-Aldrich, USA) and analytical grade redistilled water. All chemicals were filtered through $0.45 \mu \mathrm{m}$ filters prior to use (Supelco, USA). Mobile phase A:water:trifluoracetic acid (1:0.01, v/v), mobile phase B:acetonitrile:water:trifluoracetic acid (1:1:0.01, $\mathrm{v} / \mathrm{v} / \mathrm{v})$. Flow rate: $0.3 \mathrm{ml} / \mathrm{min}$. Gradient elution was applied according to the following programme: 0 min. $20 \%$ B + 80\% A, 30 min. $-40 \%$ B + 60\% A, 60 min. $-80 \%$ $\mathrm{B}+20 \%$. Injection volume: $2 \mu \mathrm{l}$. UV detection at wavelength $\lambda=280 \mathrm{~nm}$. Temperature of column: $25^{\circ} \mathrm{C}$.

\section{Preparation of samples for HPLC analysis}

Dried and powdered biomass $(0.1 \mathrm{~g})$ was used for methanol extraction $\left(10 \mathrm{ml}\right.$, for $30 \mathrm{~min}$, in $60-70^{\circ} \mathrm{C}$ water bath); this step was repeated three times. Following filtration, the extracts were combined, vacuum concentrated, and subsequently transferred into $10 \mathrm{ml}$ flasks. For HPLC analysis, a 1-ml sample was taken and after centrifugation $(14000 \mathrm{~g}, 10 \mathrm{~min})$ and filtration $(0.45 \mu \mathrm{m})$ was injected into the column.

\section{Standards and reagents}

Methanol and acetonitrile were purchased from POCH (Gliwice, Poland), trifluoracetic acid from SigmaAldrich (USA). Reference standards of the tested compounds were purchased from the following sources: acteoside, baicalin, baicalein, 7-methylether baicalein, 5,6,7-trimethylether baicalein, wogonin and chrysin from Extrasynthese (Genay, France); scutellarin and wogonin 7-O-glucuronide from Phytomarker (Tianjin, China). Standard solutions were prepared by dilution of 1-mg compound in 1-ml methanol.

\section{Statistical analysis}

All data are the mean of $n=5$ (growth profile) or $n=3$ (experiments with addition of citric acid, cork pieces and resins) independent experiments. Statistical analysis was carried out using Student's $t$-test or MannWhitney test. Probability of $P<0.05$ was considered significant. Analysis was performed using the SigmaStat 3.5 program (Statcon, Germany).

\section{Results and discussion}

Preliminary experiments concentrated on developing wild type root cultures of five species from the genus Scutellaria, namely: S. barbata, S. lateriflora, S. orientalis, S. albida and $S$. altissima, with the use of various culture media (MS, SH and B5 supplemented with IBA) (Tab. 1). Preliminary chromatographic and densitometric analyses in the range of polyphenolic compounds content were performed for the obtained biomasses (Fig. 1).

Among the five species studied here, S. barbata root culture had the best growth and highest productivity of biologically active flavones, as confirmed by HPLC analysis.

The quoted literature (Baiza et al., 1998; Wu et al., 2008; Baskaran and Jayabalan, 2009; Wadegaonkar et al., 2006; Ghosh et al., 2002; Khalafalla et al., 2009; Nishikawa et al., 1999) show that untransformed root cultures are mainly cultivated on liquid media supplemented with auxin (IBA) or a combination of other phytohormones, e.g. NAA, IAA.

MS medium, regardless of the concentration of IBA added, was lethal for the $S$. barbata root culture. On SH and B5 media with high concentrations of IBA, the culture had a tendency to form callus. The best growth was observed on SH and B5 media supplemented with IBA at a concentration of $1.0 \mathrm{mg} / \mathrm{l}$. Nontransformed root cultures of $S$. barbata grew faster on SH (increase in fresh weight by ca. 8.1 fold) than on B5 medium (increase ca. 7.1 fold).

The root culture cultivated on SH medium with $1.0 \mathrm{mg} / \mathrm{l} \mathrm{IBA}$ was characterized by a stable growth rate during a 60-days cycle. During the time of growth, the following were particularly visible: the delay phase, characterized by a slower growth due to the adaptation of culture (up to the $10^{\text {th }}$ day of culture) and the log phase. The doubling time of the culture was approximately 20 days (Fig. 2). In the growth cycle of roots 
Table 1. Growth of wild type root cultures of five studied species from the genus Scutellaria

\begin{tabular}{l|c|c|c}
\hline \multirow{2}{*}{ Species } & \multicolumn{3}{|c}{ Nutrient medium } \\
\cline { 2 - 4 } S. barbata & MS-IBA $1.0(\mathrm{mg} / \mathrm{l})$ & SH-IBA $1.0(\mathrm{mg} / \mathrm{l})$ & B5-IBA 1.0 (mg/l) \\
\hline S. lateriflora & - & +++ & +++ \\
\hline S. altissima & + & - & - \\
\hline S. albida & - & - & - \\
\hline S. orientalis & ++ & - & - \\
\hline
\end{tabular}

Abbreviations: +++ - very good growth; ++ - good growth; + - poor growth; - no growth
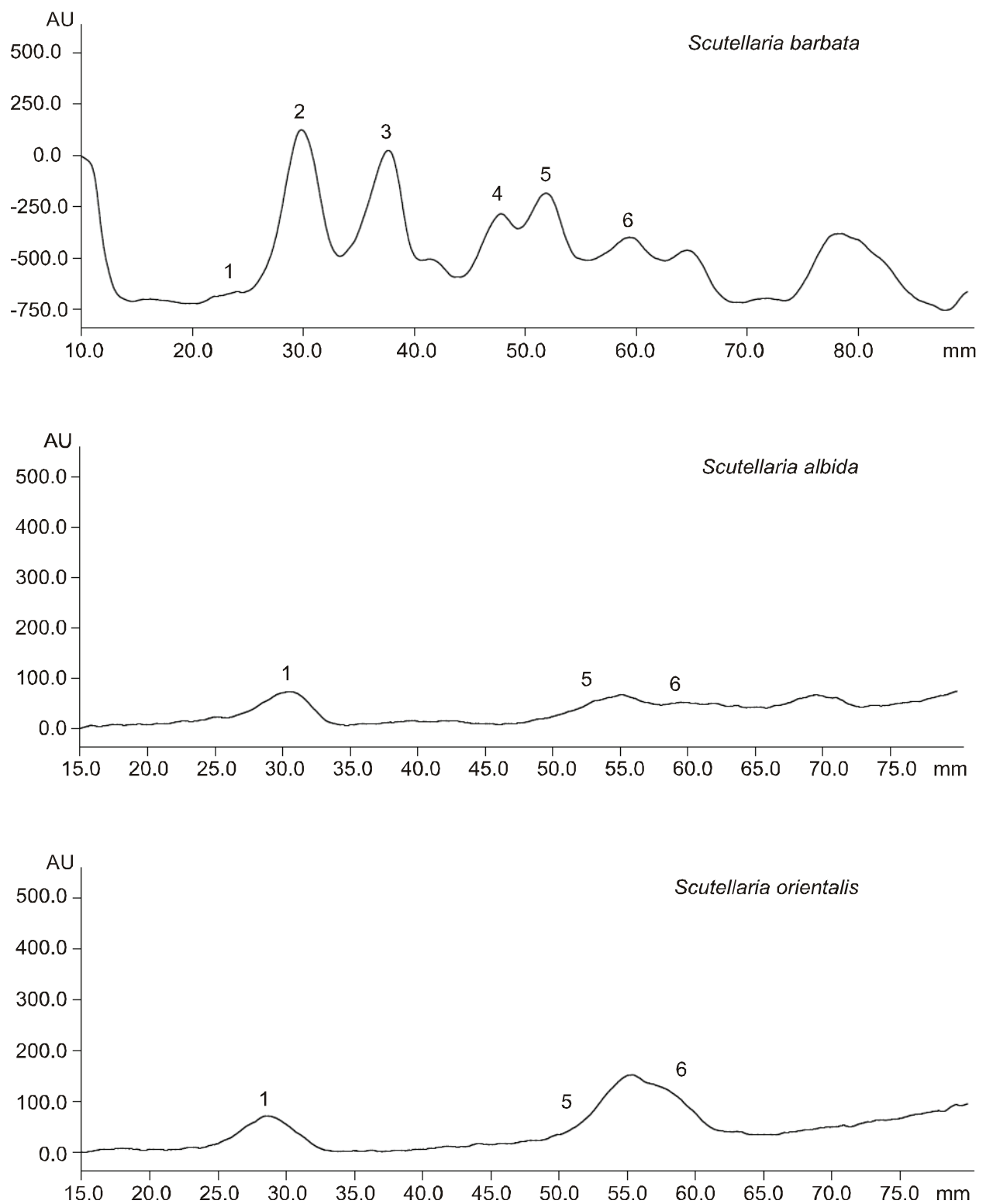

Fig. 1. Densitograms of: methanol extract from: Scutellaria barbata wild type root culture cultivated on B5-IBA $1.0 \mathrm{mg} / 1$ liquid medium. 1 - chrysin, 2 - wogonin, 3 - baicalein, 4 - luteolin, 5 - wogonoside, 6 - baicalin (A); methanol extract from Scutellaria albida wild type root culture cultivated on MS-IBA $1.0 \mathrm{mg} / 1$ liquid medium: 1 - chrysin, 5 - wogonoside, 6 - baicalin (B); methanol extract from Scutellaria orientalis wild type root culture cultivated on MS-IBA $1.0 \mathrm{mg} / 1$ liquid medium: 1 - wogonin, 5 - wogonoside, 6 - baicalin (C) 


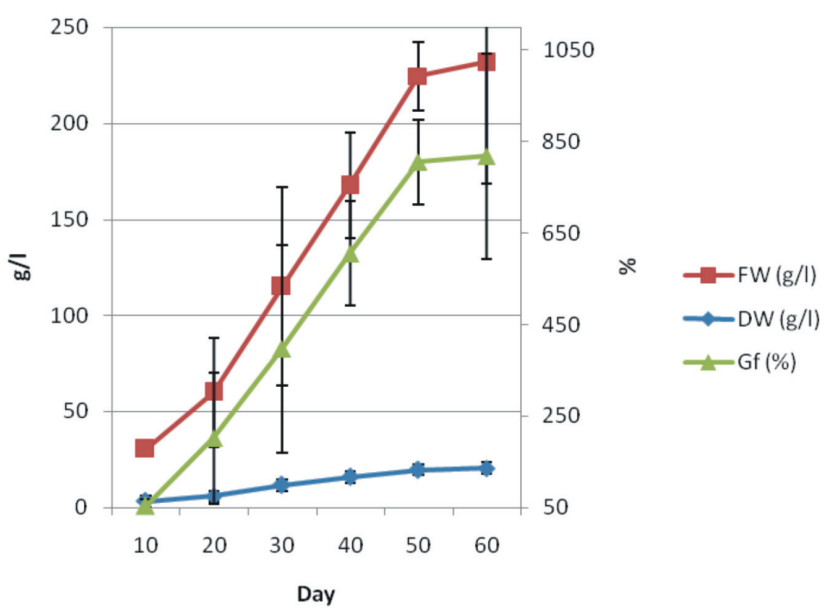

Fig. 2. Time course of growth of Scutellaria barbata wild type root cultures cultivated on SH-IBA $1.0 \mathrm{mg} / \mathrm{l}$ in a 60-days cycle (values are means $\pm \mathrm{SD}, n=5$ )

grown on B5 medium with $1.0 \mathrm{mg} / \mathrm{l} \mathrm{IBA}$ there was no delay phase and the culture was characterized by a stable growth until the stationary phase $\left(50^{\text {th }}\right.$ day of culture) - Figure 3.

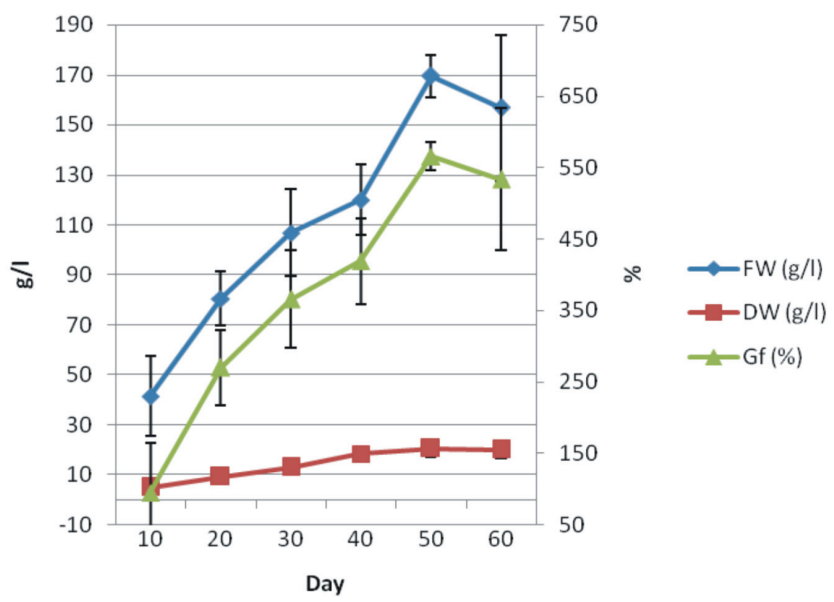

Fig. 3. Time course of growth of Scutellaria barbata wild type root cultures cultivated on B5-IBA $1.0 \mathrm{mg} / \mathrm{l}$ in a 60 -days cycle (values are mean $\pm \mathrm{SD}, n=5$ )

In the time course of secondary metabolites production, both on B5 and SH supplemented with IBA $(1.0 \mathrm{mg} / \mathrm{l})$, the dominating metabolites were flavone glycosides - wogonoside and baicalin, with low concentrations of aglycones - wogonin, baicalein and chrysin (Fig. 4). Two other compounds, namely 7-methylether baicalein and 5,6,7-trimethyether baicalein were present in traces and were not quantitatively determined. Wogono- side after acidic hydrolysis could have been the source of aglycone - wogonin - which has multidirectional activities such as: anticancer, antioxidant, antiinflammatory and antiviral, mainly against hepatitis type B virus (HBV) (Wilczańska-Barska, Chmura and Krauze-Baranowska, unpublished data).

Moreover, both cultures were characterized by a high content of phenylpropanoid - acteoside. This compound was earlier identified, among others, in $\mathrm{Scu}$ tellaria baicalensis suspension and hairy root cultures as well as in S. orientalis, S. lateriflora, S. galericulata callus cultures (Nishikawa et al., 1999). Acteoside has varied pharmacological activities, e.g. antioxidant and antiinflammatory (Wilczańska-Barska, 2010).

Two-year observations indicated that the root culture cultivated on SH medium, in contrast to B5 medium (both supplemented with $1.0 \mathrm{mg} / 1$ of IBA), was marked by a lower stability of flavones biosynthesis. The average contents of dominating compounds (on the $60^{\text {th }}$ day) on SH medium were estimated as follows: acteoside $2.98 \%$, baicalin $-2.17 \%$, wogonoside $-1.71 \%$ and the total productivity of flavones - $999 \mathrm{mg} / \mathrm{l}$; however, the maximal achieved contents were: acteoside (3.04\%), baicalin $(2.77 \%)$ and wogonoside $(3.78 \%)$ and the total productivity of flavones was $1300 \mathrm{mg} / \mathrm{l}$.

The contents of compounds on B5 medium were higher or comparable to those on $\mathrm{SH}$ medium and were as follows: acteoside $-3.79 \%$, baicalin $-3.6 \%$, wogonoside $-1.52 \%$, which resulted in a higher productivity of flavones $-1120 \mathrm{mg} / \mathrm{l}$. The maximal productivity of the culture counted as the sum of flavones amounted to $1500 \mathrm{mg} / \mathrm{l}$. The culture was characterized by a high variability in wogonoside accumulation which ranged from $1.29 \%$ to $3.42 \%$.

According to quoted literature (Tiwari et al., 2008; Kuzovkina et al., 2001) the dominating metabolites in $S$. baicalensis hairy root cultures were also flavone glycosides - baicalin and wogonoside. The highest baicalin content has been determined in hairy root cultures (Tiwari et al., 2008), where it accounted for $30 \%$ of the roots dry weight. Kuzovkina and co-workers (2001) obtained fastgrowing hairy root cultures (an increase in fresh weight of ca. 20 to 30 -fold in a 40 days cycle) with the total flavones content of ca. $5 \%$ and productivity ca. $500 \mathrm{mg} / \mathrm{l}$. In wild-type $S$. baicalensis roots, $10-15 \%$ total content of flavones is achieved after 5-10 years of growth (Kuzovkina et al., 2001). 


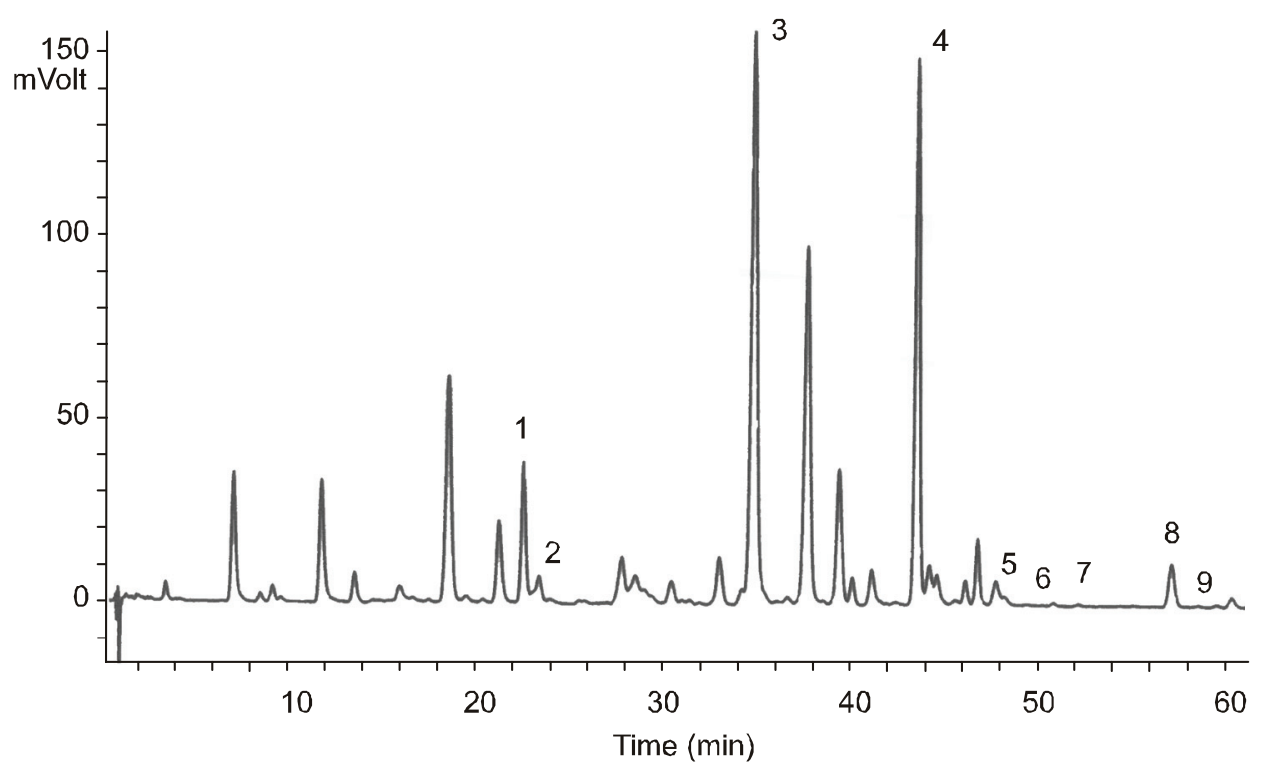

Fig. 4. HPLC chromatogram of methanol extract obtained from Scutellaria barbata wild type root cultures maintained on B5-IBA $1.0 \mathrm{mg} / 1$ medium: 1 - acteoside, 2 - scutellarin, 3 - baicalin, 4 - wogonoside, 5 - baicalein, 6-7 - methylether baicalein, 7 - 5,6,7-trimethylether baicalein 8 - wogonin, 9 - chrysin

Table 2. Growth parameters of Scutellaria barbata wild type root culture cultivated on B5-IBA $1.0 \mathrm{mg} / \mathrm{l}$ medium in the presence of cork and under control conditions (values are means $\pm \mathrm{SD}, n=3$ )

\begin{tabular}{c|c|c|c|c}
\hline \multirow{2}{*}{$\begin{array}{c}\text { Concentration of cork } \\
\text { in medium }(\mathrm{mg} / \mathrm{ml})\end{array}$} & \multicolumn{4}{|c}{ Growth parameters of root culture } \\
\cline { 2 - 5 } & Increase $\pm \mathrm{SD}$ & $\mathrm{DW}(\mathrm{g} / \mathrm{l}) \pm \mathrm{SD}$ & $\mathrm{FW}(\mathrm{g} / \mathrm{l}) \pm \mathrm{SD}$ & $\mathrm{Gf}(\%) \pm \mathrm{SD}$ \\
\hline 1 & $8.52 \pm 1.37$ & $21.42 \pm 1.18$ & $206.76 \pm 24.89$ & $751.76 \pm 137.44$ \\
\hline 3 & $8.23 \pm 0.57$ & $22.62 \pm 0.57$ & $200.21 \pm 11.63$ & $722.63 \pm 57.15$ \\
\hline 5 & $8.86 \pm 0.87\left(^{*}\right)$ & $23.40 \pm 0.58\left(^{*}\right)$ & $215.62 \pm 32.24\left(^{*}\right)$ & $786.44 \pm 87.04\left(^{*}\right)$ \\
\hline 7 & $9.43 \pm 0.70\left(^{*}\right)$ & $26.68 \pm 2.80\left(^{*}\right)$ & $239.75 \pm 28.79\left(^{*}\right)$ & $843.28 \pm 69.83\left(^{*}\right)$ \\
\hline Control & $7.1 \pm 1.17$ & $19.28 \pm 2.32$ & $174.85 \pm 31.55$ & $609.71 \pm 116.96$ \\
\hline
\end{tabular}

Means with * are statistically different at $P<0.05$

During the cultivation of root cultures on both the media, browning of the nutrient medium was observed. It was probably due to the release of phenolic compounds into the medium (Prakash et al., 2006). This process was more intensive on B5 medium especially when larger inoculums were applied. It resulted in systematic browning of biomass and growth inhibition, and caused difficulties in maintaining the continuity of the culture. In order to reduce the negative effect of such compounds in the medium, experiments with the addition of an antioxidative agent - citric acid (Prakash et al., 2006), adsorbents - Amberlite XAD 4 and XAD 7 resins as well as cork pieces (Kirakosyan et al., 2006) were performed.

A review of literature shows that cork is used as an abiotic elicitor with absorbing properties and has a multi- directional influence on secondary metabolite production of, among others, flavones (Kirakosyan et al., 2006; Yamamoto et al., 2001; Zhao et al., 2003; Zhao et al., 2004). Cork pieces were added to Sophora flavescens suspension cultures to increase sophoraflavanone $\mathrm{G}$ accumulation (Zhao et al., 2003), Glycyrrhiza gabra - isoflavone glycosides and chalcones production (Yamamoto et al., 2001), Caesalpinia pulcherrina - 2'-methoxybonducellin production (7-fold growth) (Zhao et al., 2004) and to Hypericum perforatum shoot cultures - pseudohypericin accumulation (3-fold growth) (Kirakosyan et al., 2000). Cork tissue and Amberlite resins were used in hydroponically grown Pueraria montana (Kudzu) seedlings. In the presence of cork, a 7-fold increase in daidzein and genistein production, with a 5-8 fold decrease 
Table 3. Compounds and their productivity in Scutellaria barbata wild type root culture maintained on B5-IBA $1.0 \mathrm{mg} / \mathrm{lmedium}$ in the presence of cork and under control conditions (values are means $\pm \mathrm{SD}, n=3$; Acteoside $(\bullet)$ - phenylpropanoid glycoside)

\begin{tabular}{|c|c|c|c|c|c|c|c|c|c|}
\hline \multirow{2}{*}{$\begin{array}{l}\text { Concentration } \\
\text { of cork in medium } \\
(\mathrm{mg} / \mathrm{ml})\end{array}$} & \multicolumn{7}{|c|}{ Content of analyzed compounds in root culture ( $\mathrm{g} / 100 \mathrm{~g} \mathrm{DW})$} & \multirow{2}{*}{$\begin{array}{l}\text { Sum } \\
\text { of flavones }\end{array}$} & \multirow{2}{*}{$\begin{array}{l}\text { Culture productivity } \\
\text { (mg/l; sum of flavones) }\end{array}$} \\
\hline & Acteoside $(\bullet)$ & Scutellarin & Baicalin & Wogonoside & Baicalein & Wogonin & Chrysin & & \\
\hline 1 & $\begin{array}{c}3.96 \\
\pm 0.53\end{array}$ & $\begin{array}{c}0.43 \\
\pm 0.06\end{array}$ & $\begin{array}{c}3.51 \\
\pm 0.47\end{array}$ & $\begin{array}{c}1.57 \\
\pm 0.17\end{array}$ & $\begin{array}{c}0.02 \\
\pm 0.006\end{array}$ & $\begin{array}{c}0.18 \\
\pm 0.03\end{array}$ & $\begin{aligned} & 0.003 \\
\pm & 0.0006\end{aligned}$ & $\begin{array}{r}5.713 \\
\pm 0.69\end{array}$ & $\begin{array}{l}1232.28 \\
\pm 180.2\end{array}$ \\
\hline 3 & $\begin{array}{c}3.59 \\
\pm 0.39\end{array}$ & $\begin{array}{c}0.4 \\
\pm 0.04\end{array}$ & $\begin{array}{c}3.28 \\
\pm 0.21\end{array}$ & $\begin{array}{c}1.51 \\
\pm 0.15\end{array}$ & $\begin{array}{c}0.04 \\
\pm 0.01\end{array}$ & $\begin{array}{c}0.21 \\
\pm 0.04\end{array}$ & $\begin{array}{c}0.002 \\
\pm 0.0005\end{array}$ & $\begin{array}{l}5.442 \\
\pm 0.34\end{array}$ & $\begin{array}{l}1238.33 \\
\pm 51.35\end{array}$ \\
\hline 5 & $\begin{array}{c}3.19 \\
\pm 0.05\end{array}$ & $\begin{array}{c}0.34 \\
\pm 0.006\end{array}$ & $\begin{array}{c}3.05 \\
\pm 0.15\left(^{*}\right)\end{array}$ & $\begin{aligned} & 1.3 \\
\pm & 0.05\end{aligned}$ & $\begin{array}{c}0.02 \\
\pm 0.01\end{array}$ & $\begin{array}{c}0.14 \\
\pm 0.05\end{array}$ & $\begin{array}{c}0.002 \\
\pm 0.0006\end{array}$ & $\begin{array}{l}4.852 \\
\pm 0.03\end{array}$ & $\begin{array}{c}1143.59 \\
\pm 26.8\end{array}$ \\
\hline 7 & $\begin{array}{c}2.52 \\
\pm 0.39\left(^{*}\right) \\
\end{array}$ & $\begin{array}{c}0.27 \\
\pm 0.04\left(^{*}\right) \\
\end{array}$ & $\begin{array}{c}2.37 \\
\pm 0.39\left(^{*}\right) \\
\end{array}$ & $\begin{array}{c}1.07 \\
\pm 0.15\left(^{*}\right) \\
\end{array}$ & $\begin{array}{c}0.02 \\
\pm 0.01 \\
\end{array}$ & $\begin{array}{c}0.18 \\
\pm 0.05 \\
\end{array}$ & $\begin{array}{l}0.003 \\
\pm 0.0005 \\
\end{array}$ & $\begin{aligned} & 3.913 \\
& \pm 0.58\left(^{*}\right) \\
&\end{aligned}$ & $\begin{array}{r}1066.28 \\
\pm 261.89 \\
\end{array}$ \\
\hline Control & $\begin{array}{c}3.79 \\
\pm 0.57\end{array}$ & $\begin{array}{l}0.47 \\
\pm 0.1\end{array}$ & $\begin{array}{c}3.6 \pm \\
0.42\end{array}$ & $\begin{array}{c}1.52 \\
\pm 0.29\end{array}$ & $\begin{array}{c}0.07 \\
\pm 0.05\end{array}$ & $\begin{array}{c}0.28 \\
\pm 0.12\end{array}$ & $\begin{array}{c}0.004 \\
\pm 0.001\end{array}$ & $\begin{array}{c}5.944 \\
\pm 0.88\end{array}$ & $\begin{array}{r}1119.79 \\
\pm 147.39\end{array}$ \\
\hline
\end{tabular}

Means with * are statistically different at $P<0.05$ 
in glycosides conjugates accumulation and excretion of compounds into the growth medium was observed. How ever, the addition of Amberlite XAD 4 resins upregulated the accumulation of the isoflavone glycosides by approximately 1.5-fold (Kirakosyan et al., 2006).

Our experiments demonstrated that the addition of citric acid to both the growth media in all tested concentrations $(50,75$ and $100 \mathrm{mg} / \mathrm{l})$ did not change the color of the media and did not significantly influence the time course of the root culture growth, in contrast to the content and culture productivity, which were lower or comparable to the controls.

The addition of Amberlite XAD 4 and XAD 7, resins and cork pieces to $S$. barbata wild type root cultures caused the binding of compounds released into the medium (Kirakosyan et al., 2006). No changes in metabolic profiles were observed.

Cork tissue was added to both the nutrient media at concentrations of $1,3,5$ and $7 \mathrm{mg} / \mathrm{ml}$ of the medium. Depending on the type of medium and concentration of elicitor added, a different influence on the tissue was observed. On B5 medium at concentrations of 5 and $7 \mathrm{mg} / \mathrm{ml}$, cork stimulated the tissue growth which was the best at the highest cork concentration (ca. 9.4 fold) (Tab. 2), whereas on SH medium, cork pieces inhibited the culture growth. However, an addition of cork to both the growth media did not increase the content of flavones and acteoside. Despite the stimulating influence of cork added to the root tissue cultivated on B5 medium, culture productivity remained comparable to the control (Tab. 3), because of increased tissue hydration and lower amounts of the analyzed compounds (Tab. 2).

The next stage of experiments was the addition of Amberlite XAD 4 and XAD 7 resins to root cultures. Resins were used at concentrations of $1,2,10$ and $20 \mathrm{mg} / \mathrm{ml}$ as previously described (Kirakosyan et al., 2006).

The best growth was achieved on B5 medium with XAD 4 at a concentration of $10 \mathrm{mg} / \mathrm{ml}$ (increase ca. 9.1 fold) and on SH medium with XAD 4 at a concentration of $20 \mathrm{mg} / \mathrm{ml}$ (increase ca. 8.4 fold). Tissues cultivated with resin XAD 4 at another concentration grew comparably to the control. XAD 7 resin did not influence the growth parameters on B5 medium. On SH medium, the highest concentration of XAD 7 resin caused tissue death. A reverse relationship between the concentration of resins and the percentage content of the analyzed compounds and culture productivity were also observed.
Tissues with resins at the lowest concentrations were characterized by the highest concentrations of acteoside and flavones; however, they remained comparable to the control.

\section{Conclusions}

In this study, in vitro growth conditions for Scutellaria barbata wild type root cultures were established. Addition of cork pieces or Amberlite XAD 4 resin to B5 medium supplemented with $1.0 \mathrm{mg} / 1 \mathrm{IBA}$ increased culture growth. $S$. barbata wild type root cultures seem to be a rich source of flavones, mainly baicalin and wogonoside. The maximal (achieved) productivity of the culture cultivated on B5 medium was three times higher than the productivity of $S$. baicalensis hairy root cultures (Kuzovkina et al., 2001).

\section{References}

Baiza A.M., Quiroz A., Ruiz J.A., Maldonado-Mendoza I., Loyola-Vargas V.M. (1998) Growth patterns and alkaloid accumulation in hairy root and untransformed root cultures of Datura stramonium. Plant Cell Tiss. Org. Cult. 54: 123130.

Baskaran P., Jayabalan N. (2009) Psoralen production in hairy roots and adventitious roots cultures of Psoralea coryfolia. Biotechnol. Lett. 31: 1073-1077.

Cui X.H., Chakrabarty D., Lee E.J., Paek K.Y. (2010) Production of adventitious roots and secondary metabolites by Hypericum perforatum L. in a bioreactor. Bioresour. Technol. 101: 4708-4716.

Dai S.J., Chen M., Liu K., Jiang Y.T., Shen L. (2006) Four new neo-clerodane diterpenoid alkaloids from Scutellaria barbata with cytotoxic activities. Chem. Pharm. Bull. 54: 869872.

Dai S.J., Liang D.D., Ren Y., Liu K., Shen L. (2008) New neoclerodane diterpenoid alkaloids from Scutellaria barbata with cytotoxic activities. Chem. Pharm. Bull. 56: 207-209.

Fong S., Shoemaker M., Cadaoas J., Lo A., Liao W., Tagliaferri M., Cohen I., Shitvelman E. (2008) Molecular mechanisms underlying selective cytotoxic activity of BZL101, an extract of Scutellaria barbata, towards breast cancer cells. Cancer Biol. Ther. 7: 577-586.

Fons F., Tousch D., Rapior S., Guiffier A., Roussel J.L., Gargadennec A., Andary C. (1999) Phenolic profiles of untransformed and hairy root cultures of Plantago lanceolata. Plant Physiol. Biochem. 37: 291-296.

Ghosh B., Mukherjee S., Jha T.B., Jha S. (2002) Enhanced colchicine production in root cultures of Gloriosa superba by direct and indirect precursors of the biosynthetic. Biotechnol. Lett. 24: 231-234. 
Hu X., You J., Bao C., Zhang H., Meng X., Xiao T., Zhang K., Wang Y., Wang H., Zhang H., Yu A. (2008) Determination of total flavonoids in Scutellaria barbata D. Don by dynamic ultrasonic extraction coupled with on-line spectrophotometry. Anal. Chim. Acta 610: 217-223.

Khalafalla M.M., Daffalla H.M., El-Shemy H.A., Abdellatef E. (2009) Establishment of in vitro fast-growing normal root culture of Vernonia amygdalina - a potent African medicinal plant. Afr. J. Biotechnol. 8: 5952-5957.

Kirakosyan A., Kaufman P.B., Chang S.C., Warber S., Bolling S., Vardapetyan H. (2006) Regulation of isoflavone production in hydroponically grown Pueraria montana (kudzu) by cork pieces, XAD-4, and methyl jasmonate. Plant Cell Rep. 25: 1387-1391.

Kirakosyan A.B., Vardapetyan R.R., Charchoglyan A.G., Yamamoto H., Hayashi H., Inoue K. (2000) The content of hypericin and pseudohypericin in cell cultures of Hypericum perforatum. Russ. J. Plant Physiol. 48: 819-819.

Kuzovkina I.N., Guseva A.V., Alterman I.E., Karnachuk R.A. (2001) Flavonoid production in transformed Scutellaria baicalensis roots and ways of its regulation. Russ. J. Plant Physiol. 48: 448-452.

Lee T.K., Lee D.K., Kim D.I., Lee Y.C., Chang Y.C., Kim C.H. (2004) Inhibitory effects of Scutellaria barbata D. Don on human uterine leiomyomal smooth muscle cell proliferation through cell cycle analysis. Int. Immunopharmacol. 4: 447-454.

Nishikawa K., Furukawa H., Fujijoka T., Fuji H. (1999) Fla vone production in transformed root cultures of Scutellaria. Phytochem. 52: 885-890.

Olszowska O., Alfermann A.W., Furmanowa M. (1996) Eugenol from normal and transformed root cultures of Coluria geoides. Plant Cell Tiss. Organ Cult. 45: 273-276.

Powell C.B., Fung P., Jackson J., Dall'Era J., Lewkowicz D., Cohen I., Smith-McCune K. (2003) Aqueous extract of herba Scutellaria barbatae, a Chinese herb used for ovarian cancer, induces apoptosis of ovarian cancer cell lines. Gynecol. Oncol, 91: 332-340.

Prakash E., Sha Valli Khan P.S., Sreenivasa Rao T.J., Meru E.S. (2006) Micropropagation of red sanders (Pterocarpus santalinus L.) using mature nodal explants. J. For. Res. 11: 329-335.

Rugo H., Shitvelman E., Perez A., Vogel C., Franco S., Tan Chiu E., Melisko M., Tagliaferri M., Cohen I., Shoemaker M. et al. (2007) Phase I trial and antitumor effects of BZL101 for patients with advanced breast cancer. Breast Cancer Res. Treat. 105: 17-28.

Świąder K., Kowalczyk A., Matkowski A., Lamer-Zarawska E. (2003) Chromatographic analysis of polyphenolic compounds in Scutellaria barbata D. Don. cultivated in Poland. Herba Polon. 49: 157-160.
Tiwari R.K., Trivedi M., Guang Z.C., Guo G.Q., Zheng G.C. (2008) Agrobacterium rhizogenes mediated transformation of Scutellaria baicalensis and production of flavonoids in hairy roots. Biol. Plant 52: 26-35. RLINK www.springerlink. com/index/PK560229241N8331

Wadegaonkar P.A., Bhagwat K.A., Rai M.K. (2006) Direct rhizogenesis and establishment of fast growing normal root organ culture of Withania somnifera Dunal. Plant Cell Tiss. Organ. Cult. 84: 223-225. ERLINK www.springerlink. com/index/784026683W736Q2J

Wang Y., Xue X., Xiao Y., Zhang F., Xu Q., Liang X. (2008) Purification and preparation of compounds from an extract of Scutellaria barbata D. Don using preparative parallel high performance liquid chromatography. J. Sep. Sci. 31: 1669-1676.

Wilczańska-Barska A., Chmura B., Krauze-Baranowska M. Dotychczasowy stan badań nad aktywnością farmakologiczną flawonów $z$ rodzaju Scutellaria (article in press).

Wilczańska-Barska A., Chmura B., Krauze-Baranowska M. (2010) Akteozyd - fenylopropanoid o cennych właściwościach leczniczych. Post. Fitoter, 11: 157-161.

Wu C.H., Murthy H.N., Hahn E.J., Paek K.Y. (2008) Establishment of adventitious root co-culture of Ginseng and Echinacea for the production of secondary metabolites. Acta Physiol. Plant 30: 891-896.

Wysokińska H., Chmiel A. (2006) Produkcja roślinnych metabolitów wtórnych w kulturach organów transformowanych. Biotechnologia 75: 124-135.

Xu C.S., Leund A.W.N., Liu L., Xia X.S. (2010) LED-activated pheophorbide a induces cellular destruction of colon cancer cell. Laser Phys. 7: 544-548.

Yamamoto H., Yato A., Yazaki K., Hayashi H., Taguchi G., Inoune K. (2001) Increases of secondary metabolite production in various plant cell cultures by co-cultivation with cork. Biosci. Biotechnol. Biochem. 65: 853-860.

Yin X., Zhou J., Jie C., Xing D., Zhang Y. (2004) Anticancer activity and mechanism of Scutellaria barbata extract on human lung cancer cell line A549. Life Sci. 75: 2233-2244.

Zhao P., Hamada C., Inoune K., Yamamoto H. (2003) Efficient production and capture of 8-prenylnaringenin and leachianone $G$ - biosynthetic intermediates of sophoraflavanone $G$ - by the addition of cork tissue to cell suspension cultures of Sophora flavescens. Phytochem. 62: 1093-1099.

Zhao P., Iwamoto Y., Kouno I., Egami Y., Yamamoto H. (2004) Stimulating the production of homoisoflavonoids in cell suspension cultures of Caesalpinia pulcherrima using cork tissue. Phytochem 65: 2455-2461. 